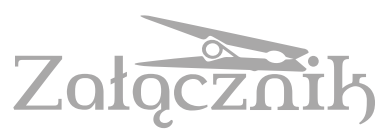

\title{
NOTES ON KITSCH IN ARCHITECTURE. AN ILLUSION OR AN ERSATZ OF HAPPINESS?
}

BARBARA SteC

Faculty of Architecture and Fine Arts,

Andrzej Frycz Modrzewski Cracow University

bara.stec@gmail.com

'Architecture is filled with kitsch!' - claimed Kurt W. Forster, an expert and a critic of architecture in an interview I conducted with him (Stec 2005: 75). At that time, eleven years ago, the notion of kitsch appeared in architecture journals predominantly in relation to controversial projects - a variety of amusement parks and shopping malls. Earlier still, in the 1980s and 1990s in Poland, the subject was considered in the context of postmodern architecture. Nowadays, the concept of kitsch is mostly present in relation to the issue of authenticity in architecture. It can, therefore, be asserted that kitsch is one more term in the vocabulary of architectural criticism and that from time to time it recurs in discussions - in its subsequent interpretations - along with phenomena it is allegedly typical of. Originally, however, kitsch did not concern architecture at all.

It is a known fact that the term 'kitsch' was introduced circa 1870 in the milieu of Munich painters to refer to paintings they considered tacky and worthless. Those paintings had their authors and buyers behind them, i.e. real people with their attitudes, it was only later that the notion of kitsch migrated to other fields of artistic activity subsequently travelling to aesthetics, philosophy and psychology. Such career of sorts of the notion indicates that the phenomenon has since the moment of its recognition engrossed art and film critics, psychologists and the artists themselves, provoking them to provide their respective reinterpretations of it. Nevertheless, the original meaning of the work 'kitsch' seems to have prevailed, while all the various philosophical accounts and artistic interpretations of kitsch do not as much alter its meaning, as specify the range of phenomena it encompasses, identifying various causes of its origination, mechanisms of its operation, as 
well as the effect it has on the life of people, society and art, while in the case of architecture - also on the architectural, urban and landscape space.

At this juncture, a question arises whether the concept of architectural kitsch should be distinguished as a separate entity or whether it suffices to merely locate it within the wider discourse on kitsch and its various manifestations throughout human life and activity? Certainly, the general profile of kitsch may also be applied within architecture. However, it is not difficult to observe that the field-specific kitsch of architecture has to be a reflection of the physical, temporary and spatial scale of architectural creations in how they relate to the physical dimensions of a human body and the lifespan of human life, as well as directly to the practical function of architecture itself. The scale of a work of architecture differs from that of a painting, sculpture, piece of literature or music. The notion of kitsch, at the moment of its origination, concerned objects of much smaller size than an average architectural object and it is still predominantly used for describing trinkets, artifacts, cheap landscape art, something that can easily be put away to a wardrobe and hence removed from view. The physical dimension of architecture makes this impossible, what is more - it entails a large scale of psychological, cultural and sociological consequences for its users and similar influence on its surroundings.

\section{ILLUSION}

In my reflections on kitsch in architecture, I would like to refer to one more opinion presented by K.W. Forster in the already cited interview; one in which he described kitsch as an illusion, thus touching upon the contemporarily discussed issue of authenticity. Forster declared:

In my opinion this notion [kitsch - B.S.] refers to the illusion that everything is great and lovely. It involves pretending that the world is like a fairy-tale, that a wife loves her husband and vice versa, that the children are well-behaved and otherwise marvelous and that such idyll exists in everyday life, whereas it simply is not true. As a desire or an illusion, such thinking can be easily transferred into an architectural form, full of dreaminess and naïveté. Such buildings are created either by or for people who do not sport the courage to look at the world realistically and see it maturely for what it really is in its complexity accessible for our perception (ibid.: 75). 
It can, therefore, be noted that Forster refers to kitsch regarded as the attitude a person has towards reality, a transpiring allusion to the thought of Theodor Adorno (1972). Thus, kitsch becomes inseparable from human valuation and does not exist in itself, outside the experienced consciousness and evaluations made by people, so - for instance - nature is devoid of it. None of the natural phenomena and elements constitute kitsch and that includes sunsets and deer in rut; they may, however, become kitsch when they become a subject of human creations or emotions, i.e. when they correspond to a specific human attitude towards them.

Deriving the concept of kitsch in architecture from a psychological and not aesthetic phenomenon (as the origin of the notion would suggest), Forster emphasizes the reason for its existence. Thereby, he notes that an evaluative assessment of a work architecture as kitsch requires an insight into the wider context of its operation: the attitude and motivation of the ordering party, the life situation of its users, its location, purpose, architectural functionality, etc. As the reason for kitsch in architecture, he identifies the illusion inherent in the naive, wishful thinking of people, an illusion which is subsequently embodied in the form of a building - devoid of any reference to the real life of its users and the real implications of its location. These may comprise borrowings from the favorite historic architectural style of the investor or from a different location, presumably of more allure than the local space might hold. As a result of such illusion, the building created ends up being seen as unauthentic and incongruous with its spatial and temporal surroundings. The question remains though if such building has to be considered kitsch?

\section{ARCHITECTURAL SCALE OF ILLUSION}

A reflection on evaluative assessment of an architectural work as kitsch with illusion as the basic criterion leads one to the aforementioned issue of the architectural scale, as well as to the functionality of architecture, i.e. its primary function. Due to the already indicated characteristics and purposes of architecture, no illusion can supplant the real fulfilment of the basic necessities ${ }^{1}$ of the users; therefore, instances of it prove ephemeral (seen

1 Włodzimierz Szewczuk (434: 1998) defines a necessity (both generally and in relation to each individual) as 'a state emerging when the optimum living conditions 
either as the rationale behind its specific form or as a mirage of usability within the field of 'playfulness'). Consolidation of an illusion within its temporal and physical surroundings, if at all attainable, leads to a situation when a work of architecture constitutes a replica of reality and is unable to meet the users' needs.

It is easy to define kitsch as illusion when it occurs outside of architecture; most of all due to the short-term influence it exerts over people. As the notion originally pertained most of all to objects in the size of a small painting, their relation with people was limited both spatially and temporally. To this day, such items, even of a relatively large size, accompany a person only during the moment they are being perceived. They do not touch a person's real needs and constitute a mere addition to the realities of their existence, within the domain of dreams and desires. Were we to extend the notion of kitsch to cover human behavior, it would be noticeable that the sense of affectation (classified as kitsch by Hermann Broch [1969]), or 'one's getting emotional about one's getting emotional' (considered kitsch by Ludwig Geisz [cf. Baumann 2005]) only lasts for an instant. In the scale which could be referred to as the traditional temporal scale of kitsch, its role consists of that very illusory creation - the pretence, an attempt to deceive oneself and others, the mix up of the real with the unreal. It is of no major significance whether such kitsch-illusion is created and perceived as a joke or as a serious development as it does not enter the domain of a person's real needs and does not pledge to fulfill them. It constitutes kitsch and its role as such is indeed illusion.

Similar is the basis of existence for the kitsch-illusion in architecture, one that could be referred to as (unconscious or programmed) kits ch in architecture, seen in buildings which people visit only occasionally and for periods of time short enough for the buildings not to enter into the domain of basic necessities of life. The spatial scale of architecture renders users of such buildings subjects to illusory forms, which they usually accept, much like they would a stage setting for a theatrical performance in which they would be both actors and spectators at the same time. However, even assuming the role of actors, they would notice that the illusion is separate from

of an organism are disrupted, thereby initiating its activity directed at achieving something that more or less reverts the conditions to the previous optimum'. 
reality, isolated from it as a mere domain of illusion. It may stimulate their behavior and sensations for a short moment, it may lead to the experience of a 'false catharsis', described by Adorno (1972), or to the state of being oblivious to reality, obstinately grey and problem-ridden. Such a kitschillusion may assume the scale of a building (Colosseo in Europa-Park, arch. Svenja Reich, Chemnitz 2004), or of a park (Piazza d'Italia, arch. Charles Moore, New Orleans 1974), or even of an entire city (Las Vegas). In terms of its influence on people, thus understood kitsch in architecture does not differ from its instances in painting or sculpture, as it functions within the temporal scale typical for the latter disciplines (i.e. occasional and temporary). However, it is different in terms of its impact on the landscape it becomes established as a replica, i.e. kitsch of an architectural scale.

I believe that in what he said, Forster had touched upon, whether mainly or peripherally, such aspect of illusion that leads to the emergence not as much of kitsch in architecture as of architectural kitsch a life-long self-deception pertaining to a home or landscape inhabited by a person. What becomes of an illusion in its architectural sense when one attempts to introduce it in order to supplant the real functionality of a home? Forster observes that the form of a house is oftentimes intended to reflect the various desires of the investors: it is to express a will to live in a different (as oppose to the actual) time or place, or of having a higher social status in terms of wealth, prestige, affiliation to a certain social stratum, etc. Such sort of illusion is by its very nature architectural, it may only surface at the level of architecture as it requires its own location and space, the duration of construction works and settling in, a large financial effort and a lasting effect on the landscape. That is the manner in which '(...) buildings are created either by or for people who do not sport the courage to look at the world realistically and see it maturely for what it is in its complexity accessible for our perception' (Stec 2005: 75). Against their sheer scale, a photograph of two family members smiling at each other, though in reality at odds, or a reprint of a Venetian landscape hanging on a wall seem completely innocent as displays of kitsch.

The Polish reality of the 1970s and 1980s provided very fertile grounds for dreaming of aesthetics different to that pervasive in the era - distant both historically and geographically. In those days, however, few had the opportunity to build their dream homes: 'a brand-new antique manor 
house,' a highlander-style cottage near Warsaw, an 'Australian' or a 'Spanish' villa in Lesser Poland. During the period of transformation more and more Poles would start to travel and identify their dreams of a better life with forms of houses typical for alien landscapes, whether Mediterranean, Scandinavian or American. Then again, must such formal borrowings in architecture be regarded as kitsch?

Not necessarily, it seems. In the case of buildings that do not by definition constitute 'the domain of illusion', its 'permanent establishment' proves rather problematic, and so is its transference into the real time and space of architecture within which people fulfill their basic needs. It is also difficult to 'translate' such an illusion into the physical dimensions of a building as its particular functions require particular and very real dimensions in space (an illusionistic painting of a room will not add to the floor area, nor will an illusion of a terrace enable one to get some fresh air). Ultimately, the needs vital for people are only met by reality. In that sense, the architecture that enables people to fulfill these functions has to be real, regardless of its form. The laws of physics also apply as real. An illusion, therefore, may pertain mostly to decoration: the wall-lining, ornaments that do not serve any structural or constructional purposes, as well as the spatial disposition of the building and the atmosphere of the architecture.

It is clear that illusion, as a dream and desire of the investor, oftentimes constituting the reason behind the formal borrowings, seldom remain s an illusion, i.e. a replica of a real, operational function of a house. Whereas, if the borrowed forms fulfill the functions required by the basic needs of the user and stimulate their life in reality, what would their illusory nature consist in? On that account, even if the original cause for creation of such forms was an illusion, their usability for meeting the real needs of a person makes the now ,embodied' illusion disappear. However, in order for such 'embodiment' to occur, the illusion has to meet some real needs of a person, i.e. the need for beauty, which cannot be replaced with an empty effect of prettiness nor a piece of information about it. A form which in reality organizes and meets the basic needs of a person is no longer an illusion, hence it cannot be kitsch as defined above either.

However, when illusion in architecture continues to be a useless replica of reality, isolated from performing any functions pertaining to the users' needs, it does constitute architectural kitsch, deepening a person's sense 
of impossibility to fulfill not only one's dreams, but even one's real needs. Ultimately, such rendition of the notion of kitsch ends up as information of a failure to fulfill rather than of fulfillment, even partial, as is the case of the so-called 'ersatz happiness'.

One could, therefore, put forth a hypothesis that the illusion in architecture, due to the latter's functional nature, as well as its temporal and spatial scale, may, but does not have to, lead to the emergence of architectural kitsch. Illusion which does not perform any architectural function associated with satiating basic needs of its users leads to the creation of a pointless replica, an actual equivalent to architectural kitsch. It proves easy to recognize as it arouses sadness and irritation in people, being a piercing testament of the scale of their frustration (it works as the information of a deficiency). Conversely, an illusion does not lead to the emergence of architectural kitsch when it has merely served as the rationale for creating a work of architecture, but later disappears in the executed (though by way of a borrowing) form which proves architecturally useful (e.g. as a veritable stage decoration or an object of aesthetic value). As a result, ornament does not have to constitute kitsch as long as it transforms an illusion into an 'ersatz of happiness'.

\section{AN ERSATZ OF HAPPINESS DOES NOT HAVE TO BE KITSCH}

An ersatz of happiness founded upon a dream or a desire of the ordering person does not have to be shoddy and built of poor quality materials. There are many instances of dreams incorporated into architectural forms which are regarded as an expression of lofty aspirations or of positive snobbery. Affluent burghers had for a long time aspired to match the living conditions enjoyed by the aristocracy. Their desire, stemming from their admiration for a specific architectural form or for foreign cultures, could become a source of inspiration and bear the fruit of eclecticism, not entirely dismissible in terms of its aesthetic value. For instance, a former royal residence the Brighton Pavilion of George IV - is one such dream, a striking allusion to Indo-Saracenic architecture (as an amalgam of the Gothic Revival with the style of the Mogul Empire), still it has been executed with masterful artistry. And even though it looks alien in the context of the local architecture, it is reminiscent of nineteenth century India, a country where many British architects were employed. The interior design of the Pavilion is a mixture 
of East Indian, Chinese and Islamic elements. Despite the inauthenticity of the palace's architecture in the context of the local townscape of Brighton, one cannot but appreciate the sheer craftsmanship and artistry of John Nash, the architect responsible for its final reconstruction. Thanks to those qualities, and partly to the history of England's colonial policies, the residence is never considered kitsch, but simply a mere eccentricity or a curiosity.

This example proves that simple inauthenticity of style does not suffice to identify a work of architecture as kitsch. The latter has to be accompanied by a characteristic rendering impossible any real use of the form derived from illusion. In the case of borrowings or ornaments such exclusion results predominantly from a failure to ensure two functions of architecture: the one associated with the need for beauty (aesthetic) and the need for a deep-seated, multi-sensory experience of architecture (i.e. that a work of architecture should ooze a fitting 'atmosphere'). Both functions remain unfulfilled with shoddy, mediocre quality craftsmanship of the ornament made with second-rate materials. Only in this manner does an illusion become kitsch: an ersatz of the dreamed-of reality turns out to be only an imitation of its image, providing nothing more than the information of a failure in attaining what it refers to, being an empty token thereof. A deliberate decision to surround oneself with such replicas indicates a person's morbid predilection for their own affectation and inertia, making one isolated from the actual opportunities offered by the real world. In the scale of architecture such replica ought to be eliminated by the real life surrounding it. Should it remain in force, it may be come to be regarded as a form of architectural pathology deforming the landscape and the lives of its users.

Different sensations altogether are aroused in people by 'an ersatz of happiness', i.e. a form built upon an illusion (a dream or a desire), but one created masterfully (in terms of its craftsmanship and sheer artistry). Regardless of the extent of its 'inauthenticity', if beautiful - it does affect people with its own beauty and not the reflected allure of another object. Thus, it becomes itself an 'ersatz of happiness' which, though a progeny of an illusion, escapes such attribution thanks to its own beauty. No longer is this to be considered kitsch either.

This reflection draws upon the concept of kitsch expounded in the works of Hermann Broch (1969), which he developed in the 1950s. According 
to him, genuine art exudes beauty, an expression of the truth and goodness, as a result of hard work, whereas in the case of kitsch the objective is supplanted by the effect of beauty, which Broch calls a decoration, an ornament. Beauty, in the Platonic sense, exists as an idea - it is in principle an unattainable model, residing outside of the system of art, the latter merely striving towards it. The 'openness' of the system, coincidental with the never-ending path towards beauty understood as the process of perception of art (i.e. the experience of it) ensures the inexhaustible potential of a work of art and its inherent attractiveness (on multiple occasions, for it does not function as a short-lasting piece of information, but as a source of harmony). Kitsch, on the other hand, turns that abstract ideal of beauty into its limited and easy to digest copy. Hence the conclusion that whereas true art cannot deplete beauty as its source, kitsch depletes it extremely quickly, a phenomenon easy to recognize in the scale of architecture.

\section{ORNAMENT IN ARCHITECTURE}

The conceptualization of kitsch put forth by Broch is well attuned to the modernist idea of architecture, according to which ornaments and decorations are treated as untrue (not serving any structural or constructional purposes) elements of a building, and therefore a replica of sorts - regardless of the quality of their craftsmanship. Today it seems rather difficult to acknowledge such a mercilessly clear-cut distinction.

Even the subsequent, post-modernist approach to ornament as an intentionally jocular citation of a different historical form seems nowadays a closed chapter in the history of architectural thought. Postmodernism itself has not as much changed the definition of ornament, as re-sanctioned its presence in architecture and elevated it to the status of a stylistic differentiator and a medium of the desired narrative. The post-modern ornament, however, does not introduce illusion into architecture for it does not imitate, but rather mocks a foreign, usually historical form; it should more precisely be understood as an 'illusion of an illusion,' which helps dismiss the charge of it being kitsch, as the latter is characterized by the ease of perception for an average, mass user of architecture. Therefore, it cannot be founded on a sophisticated intellectual inter-play.

Having experienced the eras of modernism and post-modernism, some of their manifestations still present in architecture, the contemporary 
architectural critique distances itself from identifying the architectural kitsch with ornaments. The thought currents of today, while advocating authenticity and denouncing illusion as the source of kitsch, advance a more in-depth analysis of the ornament and decoration in terms of their inherent potential of enriching the multi-sensory experience of architecture. It is principally the result of the present-day emphasis on the atmosphere of architecture as one of its basic functions. That, in turn, requires a change in the attitude towards ornament, as its 'usability' most of the time consists in this very atmosphere-creating function. Hence, the ornament as such is no longer laden with negative value that it used to be for the modernists (who saw in it an element belonging neither to constructional nor structural aspects of architecture), instead it is regarded with its roots in the category of atmosphere, thus entailing both the value of beauty, as well as people's multi-sensory experience of architecture.

The fact that the concept of kitsch is no longer applied in the context of ornament may be illustrated by a specific instance of architectural kitsch within the domain of the so-called 'minimalist-architecture'. In modern day single-family housing, loans from forms distant in time and space are seldom used as a means of fulfilling a dream or a desire, a more often chosen option is opting for one of the many styles existing in today's Poland. Minimalist forms quickly came to be recognized as indicators of prestige, wealth and luxury and as signs of the membership in a socially informal elite group of intellectuals (whereas the objective of early minimalism was rather to curb the excess and make it more moderate, restrained and unassuming in its simple forms). Although it has to be contended that in this case it is once again the craftsmanship that decides whether a particular realization may be considered an instance of kitsch, still the very existence of such examples proves that illusion and inauthenticity may also be manifested through a total rejection of ornament and decoration.

\section{CONCLUSION}

Architecture may be seen as a good field within which to establish/evaluate criteria for the identification of kitsch and its differentiation from non-kitsch. The process is facilitated by architecture's scale - both in its temporary and spatial magnitude - as well as by its necessity to fulfill the basic needs of its users. Illusion in architecture is considered kitsch, if in the executed 
form it remains nothing more than illusion - a replica of reality isolated from any need-fulfilling functions. Such illusion-kitsch deepens our sense of deficiency and the sorrow resulting from the inability to make a dream come true. What kitsch does, therefore, is to detach people from reality.

At the same time, illusion as a reason behind the creation of a specific work of architecture may evaporate in the finished form, if the latter is architecturally functional and usable. One of people's specific needs which can and should be fulfilled by architecture is the need for beauty and a deepseated (both physical and intellectual) experience of reality. For the above reason, illusion 'embodied' in a beautiful architectural form ceases to exist as illusion due to its sheer beauty; it is no longer a source of kitsch - being instead converted into an 'ersatz of happiness', able to enrich one's contact with reality, rather than divert from it, as it occurs in the case of kitsch.

\section{Bibliography}

Theodor W. Adorno (1972), Theses on the Sociology of Art, transl. B. Trench, „Working Papers in Cultural Studies”, No. 2.

Kinga Baumann (2005), O kiczu, campie i architekturze ujarzmionej pragmatyzmem, „Architektura \& Biznes”, No. 5.

Herman Broch (1969), Notes on the Problem of Kitsch (1950), [in:] KITSCH. An Anthology of Bad Taste, ed. G. Dorfles, London: Studio Vista.

Barbara Stec (2005), Powtórne spojrzenie, part 1, „Architektura \& Biznes”, No. 5. Włodzimierz Szewczuk ed. (1998), Encyklopedia psychologii, Warszawa: Fundacja Innowacja.

\section{Summary}

The article deals with kitsch in architecture. The term 'kitsch', which originally referred to images, is nowadays also used in the evaluation of architecture, especially in terms of its authenticity. This entails the consideration of the physical scale associated with an important function of architecture, to wit fulfilling the users' needs. As a starting point for the reflection serves the thought of Kurt W. Forster, identifying kitsch, including its architectural iteration, as an illusion of a better life inherent in people's dreams and desires, which may at the same time be the cause of various architectural borrowings. 
It is claimed that in architecture, due to its scale and utility, an illusion cannot supplant genuine fulfillment of the user's basic needs, therefore, it can only exist for a relatively short time either leading to the emergence of its form, or it may be solidified against reality as a useless replica, serving no function meeting the needs of its users. Such sort of kitsch can be discovered in those works of architecture in which people spend too short a time for them to require kitsch to answer their basic needs.

A prolonged experience of architectural kitsch deepens a person's feeling of sadness and irritation resulting from a sense of failure to fulfill one's dreams or even real needs. Whereas, if an illusion only serves as a cause for the creation of a work of architecture - later disappearing when its form is executed, though based upon borrowings it remains useful (for instance regarded as a theatre decoration, meeting the need for beauty and/ or a multi-sensory experience of architecture) - it can no longer be classified as architectural kitsch, i.e. as an illusion. Accordingly, ornament may also escape being seen as kitsch, if it helps convert an illusion into an ersatz of happiness.

Keywords: reality, illusion, beauty, kitsch, architecture, architectural scale, building, ornament 